Research, Society and Development, v. 9, n.2, e05921873, 2020

(CC BY 4.0) | ISSN 2525-3409 | DOI: http://dx.doi.org/10.33448/rsd-v9i2.1873

\title{
Emissão de poeira em pátio de estocagem de minério de ferro: uma abordagem ambiental e ocupacional
}

Dust emission in iron ore storage yard: an environmental and occupational approach

\author{
Emisión de polvo en patio de almacenamiento de minerales de \\ hierro: un enfoque ambiental y ocupacional
}

Recebido: 17/10/2019 | Revisado: 21/10/2019 | Aceito: 31/10/2019 | Publicado: 07/11/2019

\section{Luiz Paulo Costa Faria}

ORCID: https://orcid.org/0000-0002-5539-1251

Universidade Federal do Pará, Brasil

E-mail: lpcfaria@gmail.com

Cláudio José Cavalcante Blanco

ORCID: https://orcid.org/0000-0001-8022-2647

Universidade Federal do Pará, Brasil

E-mail: branco@ufpa.br

\section{Resumo}

A mineração provoca inúmeros impactos ao meio ambiente, e a poluição do ar causada principalmente pela poeira resultante de seus processos é um dos fatores que mais causam doenças respiratórias ocupacionais entre os trabalhadores expostos. No Brasil, áreas importantes não são cobertas pelo monitoramento ambiental da qualidade do ar, estando com a iniciativa privada estas informações. Este é o caso do Estado do Maranhão, acerca do Distrito Industrial de São Luís - DISAL. Em 2018 foi publicado um artigo com dados de um monitoramento obtido por meio de uma Rede Automática de Monitoramento da Qualidade de Ar, de uma empresa privada instalada no DISAL, cujo resultado ultrapassava os limites impostos pela legislação ambiental vigente, diante destas informações, tornou-se nosso objeto principal, avaliar quantitativamente a emissão de Poeira Respirável Ocupacional nesta mesma área, adotando uma metodologia comparativa, observando os padrões da legislação trabalhista brasileira, pois ali, trabalham muitas pessoas expostas a estas condições, em um pátio de estocagem de minério de ferro de uma grande mineradora, para posteriormente estabelecer possíveis relações entre ambas, pois, apesar do resultado ambiental ter ultrapassado os limites de tolerância referenciados, o resultado da avaliação ocupacional, classificou está mesma área 
como apta ao trabalho. Concluimos então, que a legislação ambiental foi mais restritiva que a trabalhista e considerando apenas este estudo, podemos afirmar que no tocante a poluição atmosférica, para uma área ser classificada como SALUBRE ocupacionalmente, independe do resultado ambiental desta mesma área.

Palavras-chave: Poeira, Minério, Ferro, Ocupacional, Ambiental.

\begin{abstract}
The mining activity produces several impacts to the environment. Air pollution, mainly caused by dust resulting from its processes, is one of the factors that mostly generate occupational respiratory diseases among dust exposed workers. In Brazil, important areas are not covered by environmental monitoring concerning air quality, being such information in possession of the private initiative. This is the case in the Industrial District of São Luís (DISAL), in Maranhão State. In 2018, an article was published containing information relative to a monitoring activity, obtained through an Automatic Air Quality Monitoring Network, belonging to a private company located in the DISAL. Its result exceeded the limits established by the current environmental legislation. In the light of this information, our main object became to assess quantitatively the Respirable Dust Occupational emission in that area, adopting a comparative methodology, this time in compliance with the Brazilian Labor Legislation standards, since there are many people working in that area who are exposed to such conditions in an iron ore storage yard of a large mining company. The aim was, subsequently, to establish possible relations between both of them, since the occupational assessment result has classified that area as suitable for work despite the fact that the environmental result has exceeded the tolerance limits considered as references. We conclude, therefore, that the environmental legislation was more restrictive than the labor legislation. In according, it's correct to affirm for this research that, regarding the atmospheric pollution, for an area to be classified as SALUBRE occupationally, it does not depend on the environmental result of this same area.
\end{abstract}

Keywords: Dust, Ore, Iron, Occupational, Environmental.

\title{
Resumen
}

La actividad minera produce varios impactos al medio ambiente. La contaminación del aire, causada principalmente por el polvo resultante de sus procesos, es uno de los factores que mayormente generan enfermedades respiratorias ocupacionales entre los trabajadores expuestos al polvo. En Brasil, las áreas importantes no están cubiertas por el monitoreo 
ambiental relacionado con la calidad del aire, ya que dicha información está en posesión de la iniciativa privada. Es el caso del Distrito Industrial de São Luís (DISAL), en el estado de Maranhão. En 2018, se publicó un artículo que contenía información relativa a una actividad de monitoreo, obtenida a través de una Red Automática de Monitoreo de la Calidad del Aire, perteneciente a una empresa privada ubicada en DISAL. Su resultado excedió los límites establecidos por la legislación ambiental vigente. A la luz de esta información, nuestro principal objetivo fue evaluar cuantitativamente la emisión ocupacional de polvo respirable en esa área, adoptando una metodología comparativa, esta vez en cumplimiento con los estándares de la legislación laboral brasileña, ya que hay muchas personas que trabajan en esa área expuesto a tales condiciones en un patio de almacenamiento de mineral de hierro de una gran empresa minera, ya posteriormente, establecer posibles relaciones entre ambos, ya que el resultado de la evaluación ocupacional ha clasificado esa área como adecuada para el trabajo, aunque el resultado ambiental ha excedido los límites de tolerancia considerados como referencias. Concluimos, por lo tanto, que la legislación ambiental era más restrictiva que la legislación laboral. De acuerdo con esto, es correcto afirmar para esta investigación que, con respecto a la contaminación atmosférica, para que un área sea clasificada como SALUBRE ocupacionalmente, no depende del resultado ambiental de esta misma área.

Palabras clave: Polvo, Mineral, Hierro, Ocupacional, Ambiental.

\section{Introdução}

A atmosfera terrestre é extremamente importante e necessária para a manutenção da vida no nosso planeta e suas características podem ser alteradas por meio de fenômenos naturais ou ações antropogênicas.

Na mineração, o processo de extração mineral do solo e formações rochosas, bem como toda exploração de recurso natural, provoca inúmeros impactos ambientais.

A poluição do ar, causada principalmente pela poeira que é proveniente dos trabalhos de perfuração e das etapas de beneficiamento e transporte do material minerado, em suspensão, se espalha por longas distâncias, levada pela circulação dos ventos, podendo causar impactos altamente negativos na saúde humana. 
Research, Society and Development, v. 9, n.2, e05921873, 2020

(CC BY 4.0) | ISSN 2525-3409 | DOI: http://dx.doi.org/10.33448/rsd-v9i2.1873

Geralmente, crianças e idosos são os mais afetados, devido a diminuição da capacidade pulmonar e consequentemente de seu sistema respiratório e cardiovascular, não se abstendo, toda a classe trabalhadora exposta a estes riscos.

Para embasamento científico deste estudo, formam analisados alguns artigos publicados pelo mundo, abordando temas diversos, como efeitos da poeira na saúde humana, novas tecnologias para redução de emissão de particulados, caracterização de partículas e avalições atmosféricas, como segue:

Janae et al., (2012) afirmam que há uma necessidade de se medir e entender a geração, destino e transporte de partículas transportadas pelo ar das operações de mineração, especificamente a fração de partículas mais finas.

Arasteh \& Saeedi (2016), compararam a concentração do pó de carvão disponível e a quantidade de sua toxicidade em todas as etapas da mineração, a fim de considerar o efeito negativo existente na mineração mecanizada na mina de Tabas no Irã.

Huertas et al., (2012), caracterizaram amostras de partículas transportadas pelo ar em uma região de mineração a céu aberto, utilizando técnicas de microscopia gravimétrica, eletrônica de varredura (SEM-EDS) e espectroscopia de fotoelétrons de raios X (XPS), em termos de concentração, morfologia, distribuição de tamanho de partículas (PSD) e composição elementar.

Tapia et al., (2018), realizaram ensaios de bioacessibilidade de poeiras suspensas no ar e calculou a ingestão diária, fornecendo uma avaliação preliminar dos riscos à saúde nas áreas próximas do porto de Antofagasta, localizado a $1.430 \mathrm{~km}$ ao norte de Santiago, capital do Chile.

Roberts \& Wypych (2018), descreveram algumas das diferentes técnicas e tecnologias inovadoras que estão sendo desenvolvidas e implementadas para melhorar a compressão das poeiras aerotransportadas, especificamente através do uso de sprays de micro e alta energia.

O artigo escrito por Cong et al., (2012), emprega a abordagem CFD (Computational Fluid Dynamics) para descrever o fluxo dos ventos sob diferentes direções, em pilha oval com geometria de topo plano, para estimar as emissões de poeira usando o modo de estimativa da EPA - Environmental Protection Agency dos EUA. 
Furieri et al., (2013), quantificaram a contribuição da reutilização de poeira das áreas ao redor das pilhas na emissão total de um pátio de armazenamento a céu aberto, investigando 3 ângulos de incidência do fluxo de entrada do vento sobre a pilha.

Elzinga et al., (2011), observaram a heterogeneidade na especificação de ferro no nível de partículas de poeira, e ressalta a importância de analisar um número estatisticamente adequado de partículas dentro de cada amostra, utilizando Microfiltros de raios X, para determinar a composição destas partículas.

Noble et al., (2016), consideraram aspectos da poeira mineral relacionados a todas as etapas do processo de mineração, além de medidas de controle para reduzir sua geração, técnicas de monitoração; caracterização para quantificar sua concentração, tamanho e morfologia, além da composição química e suas propriedades específicas.

Gholami et al., (2012), coletaram 5 amostras de poeira atmosférica, utilizando o método NIOSH e para a determinação da sílica utilizou o método de raios-X para posterior comparação com o padrão estabelecido na mina de ferro de Sangan, na região de Khaf, no Irã.

Goto et al., (2018) apresentaram uma avaliação da qualidade do ar nas áreas compreendidas entre o Porto do Itaqui e o Terminal Marítimo de Ponta da Madeira, localizadas no Distrito Industrial da cidade de São Luís, a partir do monitoramento dos padrões de qualidade do ar e meteorologia, fornecido por meio de uma rede de monitoramento pertencente a uma mineradora.

No Brasil, apesar dos esforços governamentais, áreas importantes do território nacional ainda não são cobertas pelo monitoramento da qualidade do ar, estando a obtenção de dados sobre este tema, nas mãos da iniciativa privada, como é o caso do Estado do Maranhão, no que se trata de informações acerca do Distrito Industrial de São Luís - DISAL.

Considerando a dificuldade de acessar dados de monitoramento de empresas privadas estabelecidas no DISAL; que nestas áreas existem vários tipos de atividades laborais sendo executadas por equipes multidisciplinares atuando diuturnamente expostos a este risco e que no trabalho de Goto et al., (2018), foi apresentado dados da qualidade do ar do DISAL, os quais indicam áreas onde os limites de tolerância para Partículas Inaláveis, foram ultrapassados, este estudo justifica-se pela oportunidade de confrontar e tornar público, as avaliações ambientais e ocupacionais obtidas especificamente nesta área em questão. 
Sendo assim, o objetivo principal deste estudo é verificar se há exposição ocupacional acima dos limites legais estabelecidos, avaliando quantativamente a emissão de Poeira Respirável, e posteriormente definir qual legislação é mais restritiva, a ambiental, orientada pela Resolução COMANA 003/1990 ou a ocupacional, regida pela Portaria MTE n. ${ }^{\circ} 3.214$ de 1978, e estabelecer possíveis relações entre ambas, especificamente nesta área em questão, a qual trata-se do pátio de estocagem de minério de ferro de uma mineradora instalada no DISAL.

É importante ressaltar, que a Legislação Trabalhista Brasileira, foi elaborada tendo por base a da NIOSHI (Instituto Nacional de Segurança e Saúde Ocupacional dos EUA) e a ACGIH (Conferência Norte-Americana de Higienistas Industriais Governamentais), e que em seu anexo 12 da NR-15, editada pela Portaria MTb n. ${ }^{\circ} 3.214$, de 08 de junho de 1978, estabelece a metodologia e limites de tolerância para poeiras minerais.

Enfim, confrontar os resultados obtidos nas duas avaliações, devidamente respeitando os padrões da legislação Ambiental e da mesma forma os da legislação Trabalhista/Ocupacional, com seus respectivos parâmetros, torna este estudo inédito, afim de evidenciar que a avalição de ambos é de suma importância para a preservação do meio Ambiente e prevenção de riscos à saúde dos trabalhadores.

\section{- Área de estudo}

De acordo com IBGE - Instituto Brasileiro de Geografia e estatística (2019), São Luís, capital do estado do Maranhão como mostra a Figura 1, localiza-se na ilha de Upaon-Açu no Atlântico Sul, entre as baías de São Marcos e São José de Ribamar. Com uma população de 1.094.667 habitantes, São Luís é o município mais populoso do Maranhão.

O clima de São Luís é tropical, quente e úmido, a temperatura mínima na maior parte do ano fica entre 22 e 24 graus e a máxima geralmente entre 30 e 34 graus e apresenta dois períodos distintos: um chuvoso, de dezembro a julho, e outro seco, de agosto a novembro.

A capital maranhense tem um forte setor industrial por conta de grandes corporações e empresas de diversas áreas que se instalaram na cidade pela sua privilegiada posição geográfica entre as regiões Norte e Nordeste do país.

Seu litoral estrategicamente localizado, permite uma grande economia de combustíveis e a redução no prazo de entrega de mercadorias provenientes do Brasil. 
Research, Society and Development, v. 9, n.2, e05921873, 2020

(CC BY 4.0) | ISSN 2525-3409 | DOI: http://dx.doi.org/10.33448/rsd-v9i2.1873

Figura 1 - Localização da cidade de São Luís - MA e área em estudo

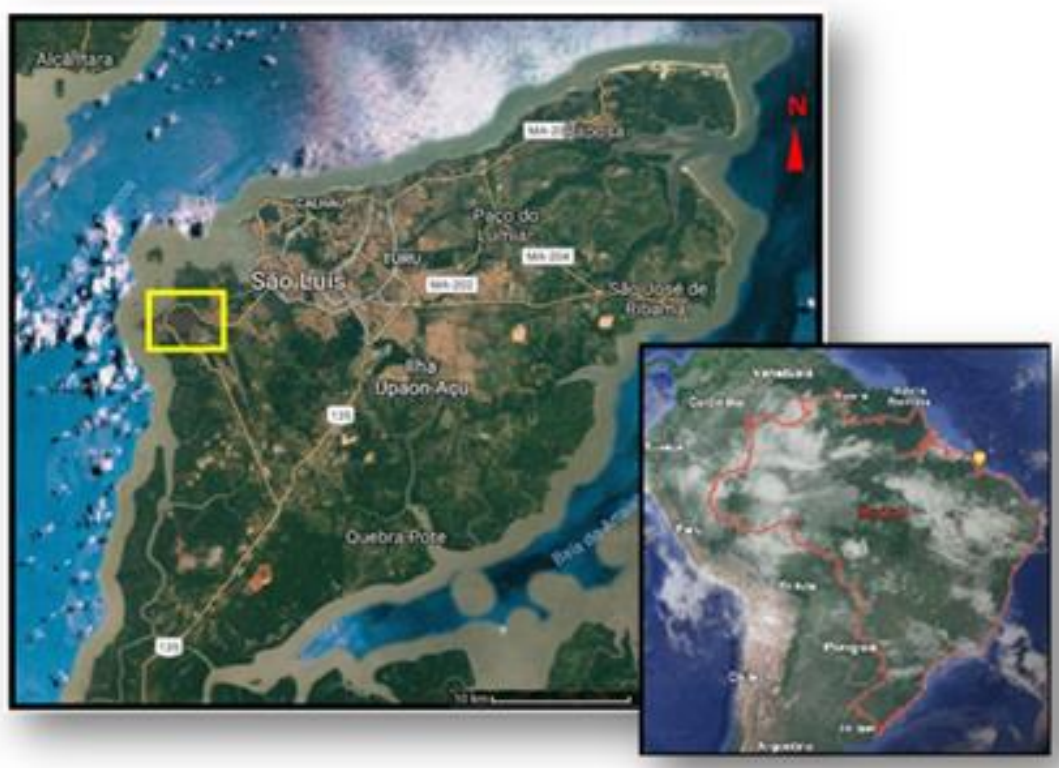

Fonte: Adaptado de Google Maps 2019

Observa-se que a cidade de São Luis está localizada em uma ilha no extremo norte da região nordeste brasileira e a área em estudo no litoral da Baia de São Marcos.

O Distrito Industrial de São Luís (DISAL) tem atualmente 107 empresas em operação, e é lá que está localizado o pátio de estocagem de minério de ferro, objeto deste estudo, onde serão avaliadas as emissões de Poeira Respirável como mostra a Figura 2.

Figura 2 - Pátio de estocagem de minério de ferro - DISAL.

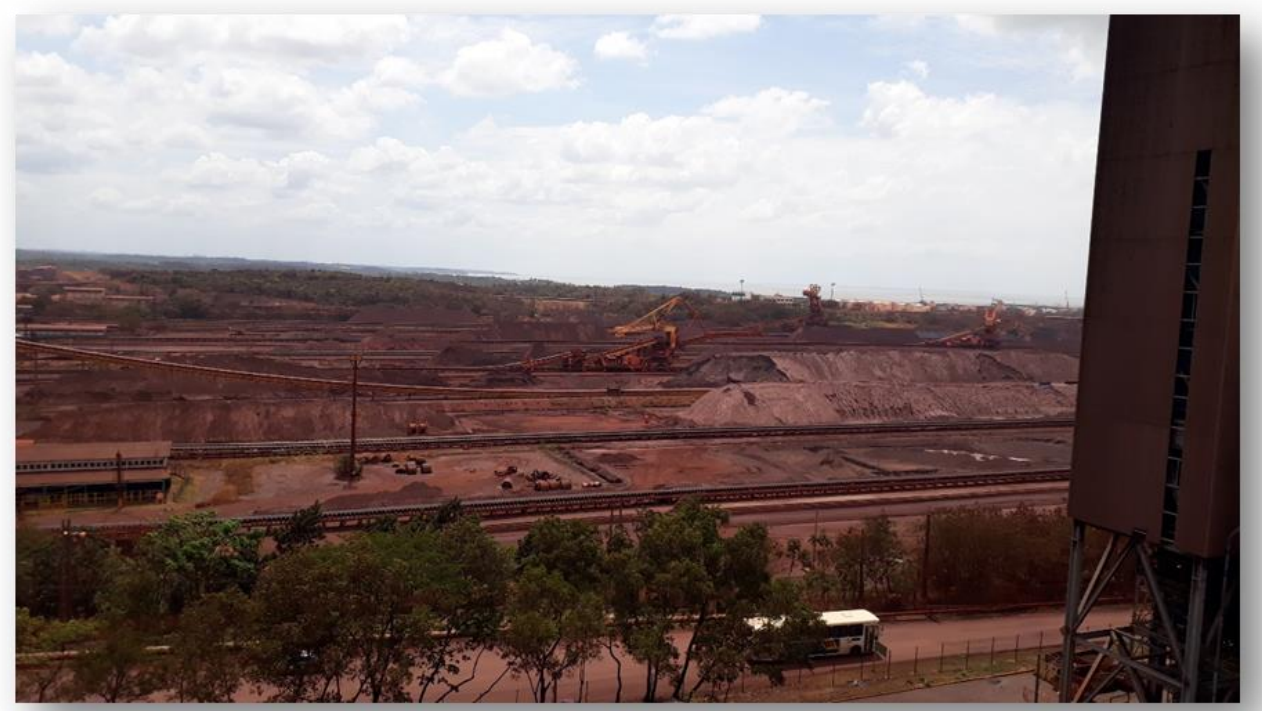

Fonte: Fotografia registrada pelo autor 
Research, Society and Development, v. 9, n.2, e05921873, 2020

(CC BY 4.0) | ISSN 2525-3409 | DOI: http://dx.doi.org/10.33448/rsd-v9i2.1873

Observa-se pela imagem que se trata de uma área aberta, sem vegetação significativa, sujeita a expressiva ação dos ventos que atuam no ambiente.

\section{Metodologia}

Para a realização deste estudo, os dados referentes à avaliação ambiental de Poeira Inalável da área em questão, foram extraídos da Tabela 6 - Resultados estatísticos de PI e PTS entre os anos de 2014 e 2017 (Goto, 2018).

Tal avaliação foi orientada pela Resolução CONAMA no 003/1990) e os equipamentos automatizados desta rede de monitoramento, utilizam o princípio de medição por absorção de Raios Beta.

Por refletirem os resultados das menores partículas monitoradas ambientalmente e ainda, por serem os únicos resultados que ultrapassaram os limites de tolerância preconizados pela legislação vigente aplicável, apenas os resultados referentes à Partículas Inaláveis das estações EMAP e Y BACANGA, serão utilizados neste estudo e estão dispostos na Tabela 3.

Para o levantamento dos dados ocupacionais, todo o processo atenderá rigorosamente a NR-15 anexo 12 da Portaria MTE n. ${ }^{\circ} 3.214$ de 1978, os quais serão explicitados abaixo.

É importante ressaltar que no início das etapas de coleta de dados em campo, para avaliação de Poeira Respirável, questões sobre direção e velocidade dos ventos e precipitação pluvial serão consideradas, para que o ambiente esteja o mais próximo possível das médias obtidas entre 2014 e 2017.

\section{- Fatores contribuintes}

Para uma avaliação eficiente de Particulados Atmosféricos, deve-se levar em consideração questões como a precipitação pluviométrica local e a direção e velocidade dos ventos na região, os quais podem influenciar significativamente os resultados obtidos.

Para tanto, estudos prévios sobre estes temas serão realizados, utilizando dados de agências governamentais.

Outro fator importante, para avaliação eficiente de Particulados Atmosféricos, é o método de análise laboratorial para caracterização das partículas de Poeira Respirável, que será realizada pelo método de Difração de Raio X, (Elzinga, 2011). 
- Precipitação Pluviométrica

O monitoramento da pluviometria será realizado com dados do INMET - Instituto Nacional de Meteorologia, obtidos na Estação 82280 localizada em São Luís - MA.

- Direção e Velocidade dos Ventos

Referente ao período de avaliação da Poeira Respirável, gráficos serão apresentados considerando as informações fornecidas no INMET - Instituto Nacional de Meteorologia, obtidos na mesma estação citada acima.

\section{- Monitoramento ocupacional}

$\mathrm{Na}$ execução do monitoramento Ocupacional, serão identificados profissionais vinculados a GHE - Grupo de Homogêneo de Exposição, com o risco químico Poeira.

Por meio do acompanhamento de O.S. - Ordem de Serviço, quando estes profissionais forem desempenhar suas atividades no pátio de estocagem de minério de ferro, os mesmos serão equipados com os aparelhos de monitoramento de Poeira Respirável, e os resultados destes monitoramentos farão parte deste estudo.

- Equipamento Monitoramento Ocupacional e sua Metodologia

Todo o monitoramento realizado para aferição de Poeira Respirável, no pátio de estocagem de minério de ferro em estudo, será realizado utilizando aparelhos do modelo GILAIR-5, exposto na Figura 3.

Figura 3 - Paradigma portando bomba de amostragem programável mod. GILAIR-5

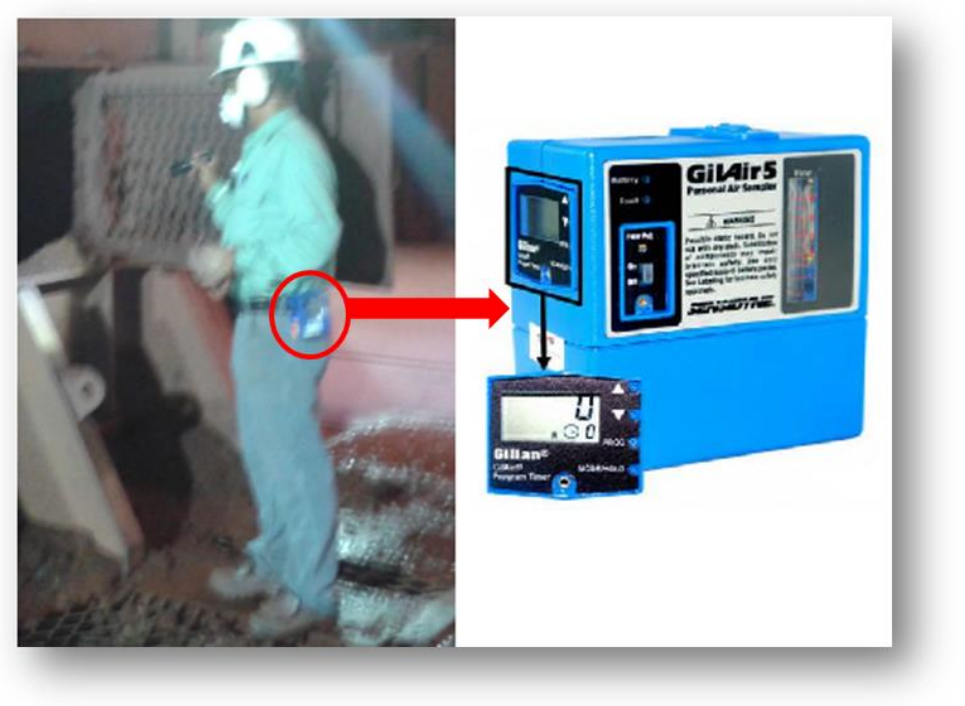

Fonte: Fotografia registrada pelo autor 
Nota-se que o aparelho de monitoramento está preso à cintura e coletor de particulados à lapela do paradigma, atendendo às boas práticas para este tipo de monitoramento.

Este aparelho de medição trata-se de uma bomba de amostragem programável, para poeira e gases com display, ajuste de tempo programável e intrinsecamente segura, devidamente aferida e calibrada.

A NHO - Norma de Higiene Ocupacional $n^{\circ}$ 08, da FUNDACENTRO, instituição de pesquisa e estudos atinentes à segurança, higiene e medicina do trabalho, vinculada ao Ministério do Trabalho, que dispõe sobre a Coleta de Material Particulado Sólido Suspenso no Ar de Ambientes de Trabalho, será rigorosamente observada neste estudo.

- Análise por difração de Raio X

Após a coleta do material particulado no pátio de estocagem de minério, as amostras serão enviadas para o laboratório da SGS, em São Paulo - SP, e submetidas à Análise por difração de Raio X, pois utiliza métodos de ensaio mineralógico eficazes na determinação de sílica livre respirável, revelando informações detalhadas sobre a composição química e a estrutura cristalográfica de suas amostras além de se mostrar muito útil para a identificação de fases de grão fino, os quais são difíceis de se identificar visualmente, (Abdollah, 2012).

A SGS, atua em todos os segmentos de indústria, na área educacional com escolas, universidades e editoras e seus laboratórios possuem equipes de mineralogistas aplicados com anos de experiência em caracterização e equipamento de última geração.

\section{- Delimitação dos pontos monitorados}

- Limite Ambiental

O monitoramento ambiental apresentado, originou-se da Rede Automática de Monitoramento da Qualidade do Ar e Meteorologia (RAMQAM) de São Luís - MA mostrado na Figura 4, composta pelas estações EMAP e Y Bacanga,

Figura 4 - Localização das torres de monitoramento e do pátio de minério de ferro 


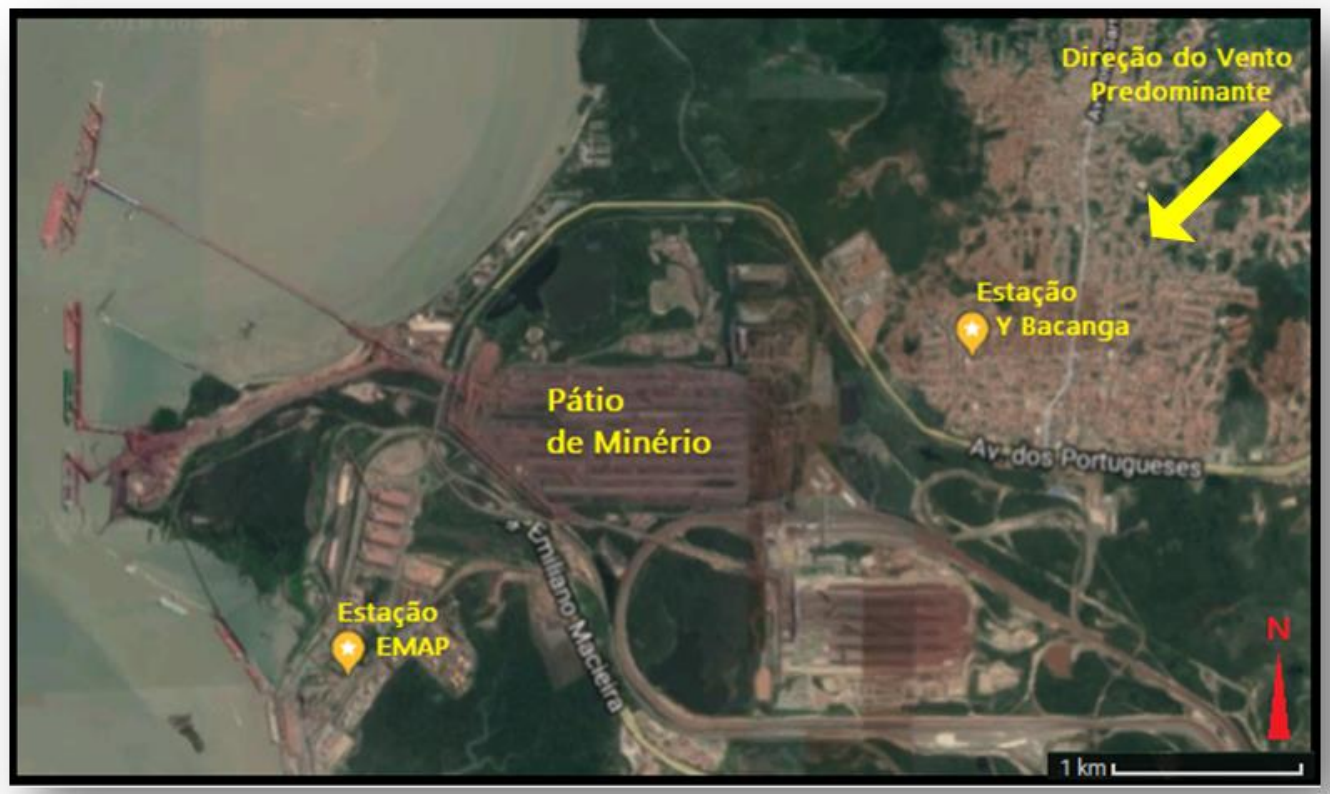

Fonte: Adaptado de Google Maps 2019

É importante observar que o pátio em estudo fica justamente entre as duas torres de monitoramento e no mesmo sentido dos ventos predominantes.

Suas coordenadas geográficas decimais estão demonstradas abaixo na Tabela 1:

Tabela 1 - Coordenadas Geodésicas Decimais das torres de monitoramento

\begin{tabular}{ccc}
\hline ESTAÇĀO & LATITUDE & LONGITUDE \\
\hline EMAP & -2.576194 & -44.366194 \\
\hline Y BACANGA & -2.561417 & -44.336250 \\
\hline
\end{tabular}

Fonte: Coletadas pelo autor

- Limite Ocupacional

A Figura 4 acima, também apresenta a localização do pátio de minério onde ocorrerá as avaliações ocupacionais de Poeira Respirável, em conformidade com a NR-15. É importante observar que esta área fica entre as estações Y Bacanga e EMAP, sendo a primeira a barlavento e a segunda sotavento deste pátio, ou seja, observando a direção do vento, a estação EMAP monitora a qualidade do ar já com a carga de particulados oriunda da área em estudo, ao contrário da estação Y Bacanga que fica antes desta área. 


\section{- Parâmetros}

- Avaliações Ambientais

Todos os resultados do monitoramento da qualidade do ar foram orientados pela legislação vigente conforme mostra a Tabela 2 Resolução CONAMA nº 003/1990.

Tabela 2 - Parâmetros mínimos Resolução CONAMA nº 003/1990

\begin{tabular}{ccccc} 
POLUENTE & $\begin{array}{c}\text { TEMPO DE } \\
\text { AMOSTRAGEM }\end{array}$ & $\begin{array}{c}\text { PADRÃO } \\
\text { PRIMÁRIO } \\
(\mu \mathrm{g} / \mathrm{m} 3)\end{array}$ & $\begin{array}{c}\text { PADRÃO } \\
\text { SECUNDÁRIO } \\
\left(\mu \mathrm{g} / \mathrm{m}^{3}\right)\end{array}$ & $\begin{array}{c}\text { MÉTODO DE } \\
\text { MEDIÇÃO }\end{array}$ \\
\hline Partículas & 24 Horas & 150 & 150 & $\begin{array}{c}\text { Separação Inercial } \\
\text { /Filtração }\end{array}$ \\
\hline Inaláveis & $\begin{array}{c}\text { Média Aritmética } \\
\text { Anual }\end{array}$ & 50 & 50 & $\begin{array}{c}\text { Separação Inercial } \\
\text { /Filtração }\end{array}$ \\
\hline
\end{tabular}

Fonte: Extraído da Resolução CONAMA 003/1990

Esta tabela evidencia os limites de tolerância referenciados pela legislação ambiental vigente, cujo padrão primário não foi atendido, conforme as avaliações ambientas observadas neste estudo.

- Avaliações Ocupacionais

Todo o embasamento para o monitoramento e avaliação da Poeira Respirável, será realizado observando as orientações da NR-15, por meio de seu anexo 12, onde a definição do Limite de Tolerância para Poeira Respirável, é dada pela equação (1):

$$
L . T .=\frac{8}{\% \text { quartzo }+2} \mathrm{mg} / \mathrm{m3}
$$

Nesta equação, onde lê-se quartzo, entenda que é resultado da avaliação de sílica livre cristalizada no ambiente avaliado e os demais componentes desta equação são empíricos. Já os limites de tolerância fixados pela NR-15 são válidos para jornadas de trabalho de até 48 (quarenta e oito) horas por semana, inclusive e para jornadas que excedem a 48 (quarenta e 
oito) horas semanais, estes limites deverão ser deduzidos, sendo estes valores fixados pela autoridade competente.

\section{Resultados e discussão}

Todos dos dados referentes ao monitoramento ambiental foram obtidos no período entre os anos de 2014 e 2017 na área em estudo.

Poeiras Inaláveis (PI), são as menores partículas monitoradas pelo sistema convencional de monitoramento Ambiental e o resultado do monitoramento realizado pode ser observado abaixo na Tabela 3.

Tabela 3 - Resultado Monitoramento Ambiental (2014 e 2017)

\section{PI - POEIRA INALÁVEL - Parâmetro - $\left(\mu \mathrm{g} / \mathrm{m}^{3}\right)$}

\begin{tabular}{cccc} 
ESTAÇÃO & ANO & $\begin{array}{c}\text { MÉDIA } \\
\text { ARITIMÉTICA } \\
\text { L.T. }\left(50 \mu \mathrm{g} / \mathrm{m}^{3}\right)\end{array}$ & $\begin{array}{c}\text { VALOR MÁXIMO } \\
24 \mathrm{HORAS} \\
\text { L.T. }\left(150 \mu \mathrm{g} / \mathrm{m}^{3}\right)\end{array}$ \\
\hline \multirow{3}{*}{ EMAP } & 2014 & 55 & 108 \\
& 2015 & 62 & 137 \\
& 2016 & 51 & 119 \\
& 2017 & 53 & 93 \\
\hline \multirow{3}{*}{ Y BACANGA } & 2014 & 43 & 71 \\
& 2015 & 39 & 908 \\
& 2016 & 31 & 61 \\
\hline
\end{tabular}

Fonte: Dados extraídos de Goto et al., (2018, p. 113)

Para melhor visualizar e interpretar estes resultados anuais de PI, elaboramos um gráfico

(Figura 5) que evidencia o não atendimento aos limites de tolerância estabelecidos como Parâmetros mínimos, pela Resolução CONAMA nº 003/1990, mostrado na Tabela 2. 
Research, Society and Development, v. 9, n.2, e05921873, 2020

(CC BY 4.0) | ISSN 2525-3409 | DOI: http://dx.doi.org/10.33448/rsd-v9i2.1873

Figura 5 - Análise do resultado monitoramento ambiental

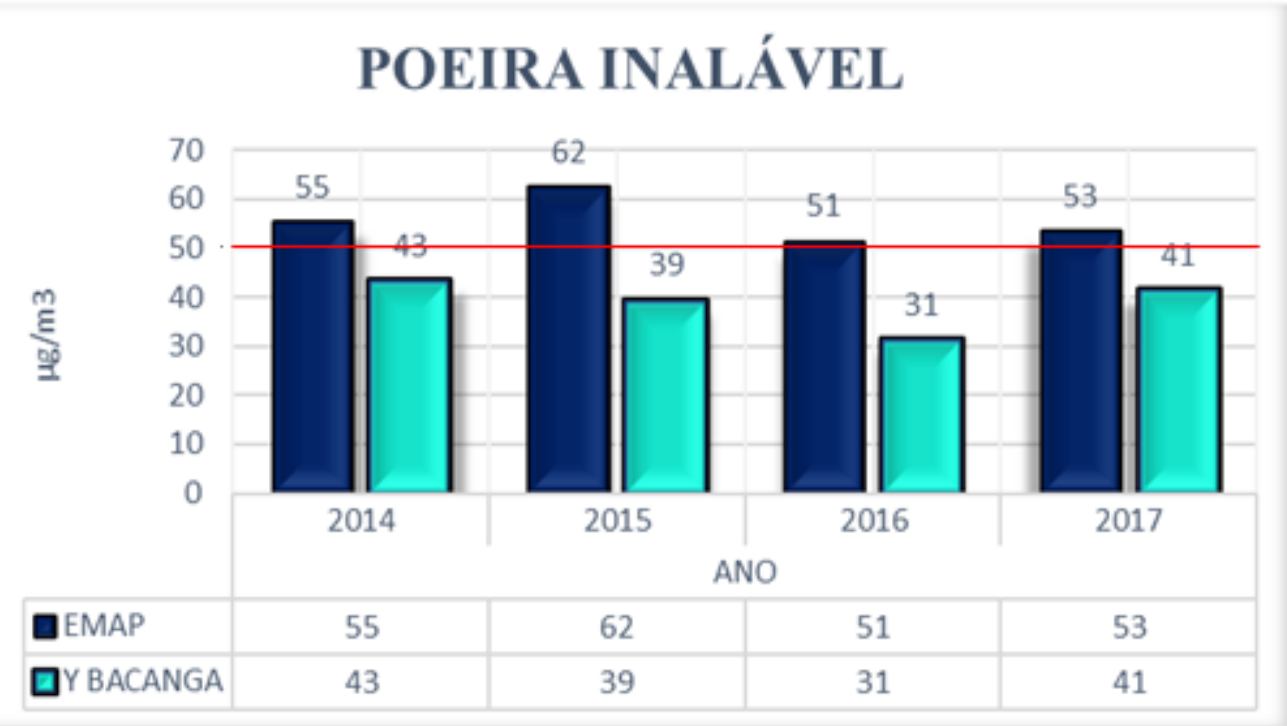

Fonte: Análise realizada pelo autor, observando a Tabela 3

Observando os resultados anuais de PI acima, verifica-se que as Médias Aritméticas de todos os anos analisados na Estação EMAP, estão acima do Limite de Tolerância estabelecido pela legislação vigente $\left(50 \mu \mathrm{g} / \mathrm{m}^{3}\right)$.

Considerando a direção dos ventos predominantes e que os resultados verificados na Estação Y Bacanga, atendem esta mesma legislação, fica evidente que a área contribuinte para o não atendimento da Resolução CONAMA n 003/1990, está entre as duas estações, exatamente onde se encontra o pátio de estocagem de minério de ferro em estudo.

- Análise da Precipitação Pluviométrica

Abaixo, na Figura 6 as Medições de Precipitação Pluviométrica entre os anos de 2014 e 2017, obtidas no INMET - Instituto Nacional de Meteorologia, na Estação 82280, localizada em São Luís - MA. 
Research, Society and Development, v. 9, n.2, e05921873, 2020

(CC BY 4.0) | ISSN 2525-3409 | DOI: http://dx.doi.org/10.33448/rsd-v9i2.1873

Figura 6 - Índices Pluviométricos referente aos anos 2014 a 2017.

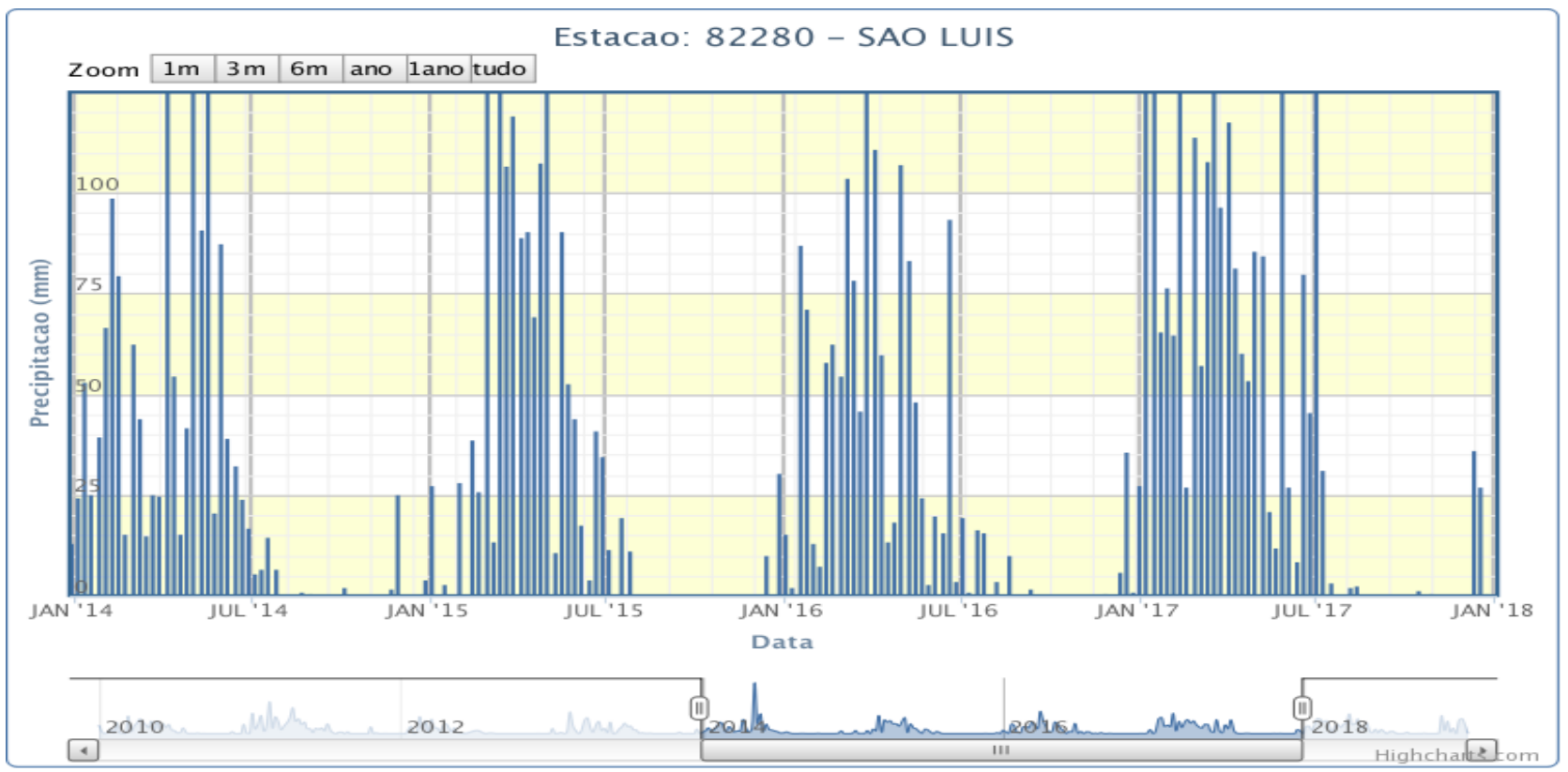

Fonte: INMET - Instituto Nacional de Meteorologia

Observando os gráficos acima, evidenciamos chuvas regulares apenas no primeiro semestre dos anos avaliados, sendo que no segundo semestre existem poucos registros de precipitação e mesmo assim, com baixo volume observado.

- Análise da Direção e Velocidade dos Ventos entre 2014 e 2017

Abaixo, na Figura 7, uma síntese da direção dos ventos, referente aos anos de 2014 a 2017, obtida no INMET - Instituto Nacional de Meteorologia, na Estação 82280, localizada em São Luís - MA. 
Research, Society and Development, v. 9, n.2, e05921873, 2020

(CC BY 4.0) | ISSN 2525-3409 | DOI: http://dx.doi.org/10.33448/rsd-v9i2.1873

Figura 7 - Direção dos ventos referente aos anos 2014 a 2017

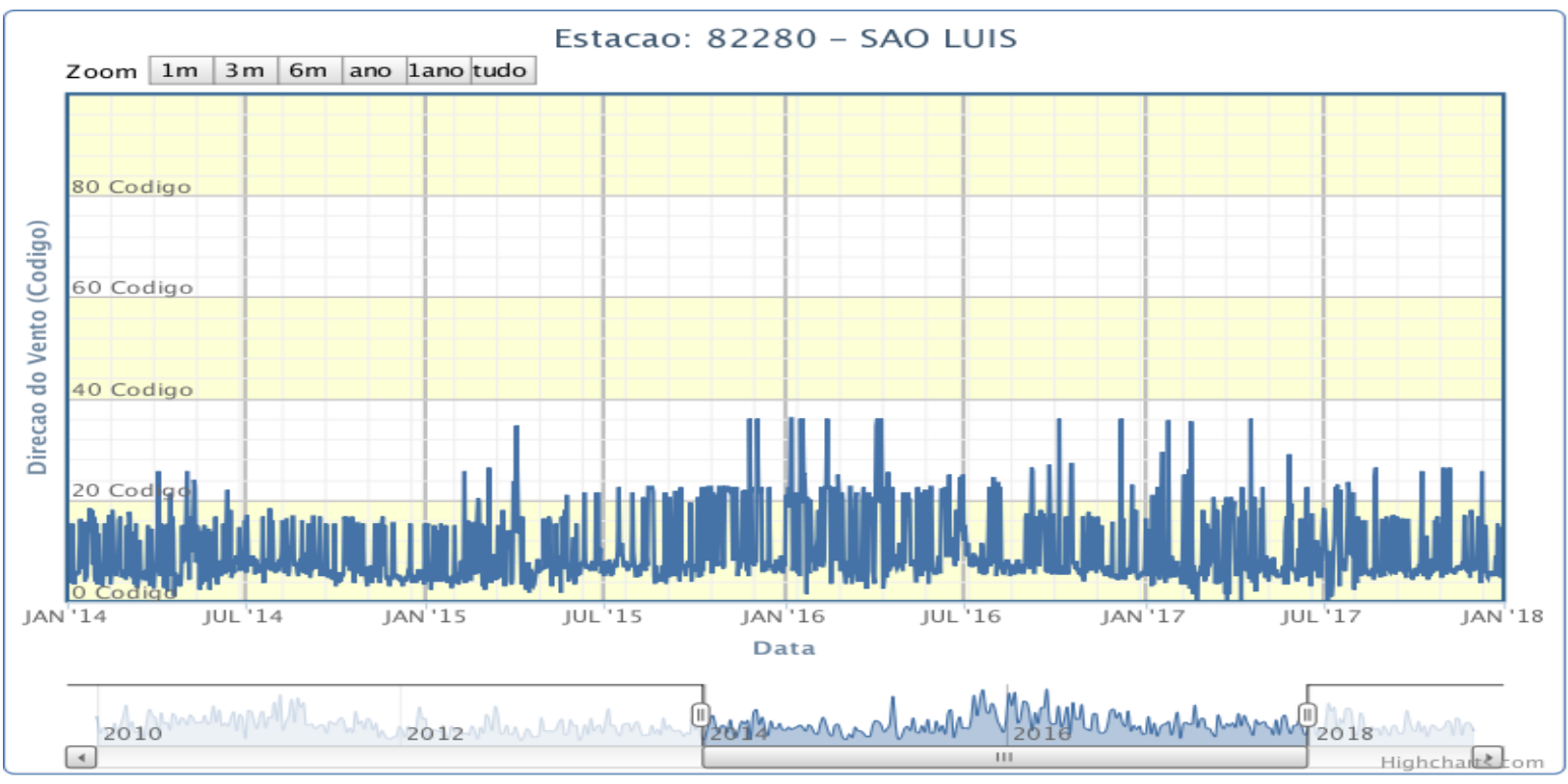

Fonte: INMET - Instituto Nacional de Meteorologia

Observa-se a ocorrência de ventos predominantes as direções Norte-Nordeste (NNE), Nordeste (NE), Leste (E) e Leste-Nordeste (ENE), de forma regular ao longo do período em estudo.

O quadro 1 demonstrado abaixo, se faz necessário para a correta leitura da direção dos ventos referente, obtida pelo sistema do INMET - Instituto Nacional de Meteorologia

Quadro 1 - Código INMET para identificação da direção dos ventos

\begin{tabular}{|cc|}
\hline CÓDIGO & SIGLA \\
\hline 0 & Calma \\
1 & NNE \\
\hline 2 & NNE \\
\hline 3 & NNE \\
\hline 4 & NNE \\
\hline 5 & NE \\
\hline 6 & NE \\
7 & ENE \\
\hline
\end{tabular}

\begin{tabular}{|cc|}
\hline CódIGO & SIGLA \\
\hline 8 & ENE \\
9 & E \\
10 & E \\
11 & ESE \\
12 & ESE \\
13 & ESE \\
14 & SE \\
15 & SE \\
\hline
\end{tabular}

\begin{tabular}{|cc|}
\hline CÓDIGO & SIGLA \\
\hline 16 & SSE \\
17 & SSE \\
18 & S \\
19 & S \\
20 & SSW \\
21 & SSW \\
22 & SSW \\
23 & SW \\
\hline
\end{tabular}

\begin{tabular}{|cc|}
\hline CÓDIGO & SIGLA \\
\hline 24 & SW \\
25 & WSW \\
26 & WSW \\
27 & W \\
28 & W \\
29 & WNW \\
30 & WNW \\
31 & WNW \\
\hline
\end{tabular}

\begin{tabular}{|cc|}
\hline CÓDIGO & SIGLA \\
\hline 32 & NW \\
33 & NW \\
34 & NNW \\
35 & NNW \\
36 & N \\
99 & Variável \\
& \\
& \\
\end{tabular}

Fonte: INMET - Instituto Nacional de Meteorologia

Nota-se que nos gráficos do INMET - Instituto Nacional de Meteorologia, a direção dos ventos é apresentada em códigos, e as direções equivalentes a estes códigos, podem ser identificadas com o auxílio deste quadro. 
Research, Society and Development, v. 9, n.2, e05921873, 2020

(CC BY 4.0) | ISSN 2525-3409 | DOI: http://dx.doi.org/10.33448/rsd-v9i2.1873

Abaixo na Figura 8, uma síntese da velocidade dos ventos, referente aos anos de 2014 a 2017, obtida no INMET - Instituto Nacional de Meteorologia, na Estação 82280, localizada em São Luís - MA.

Figura 8 - Velocidade dos ventos referente aos anos 2014 a 2017

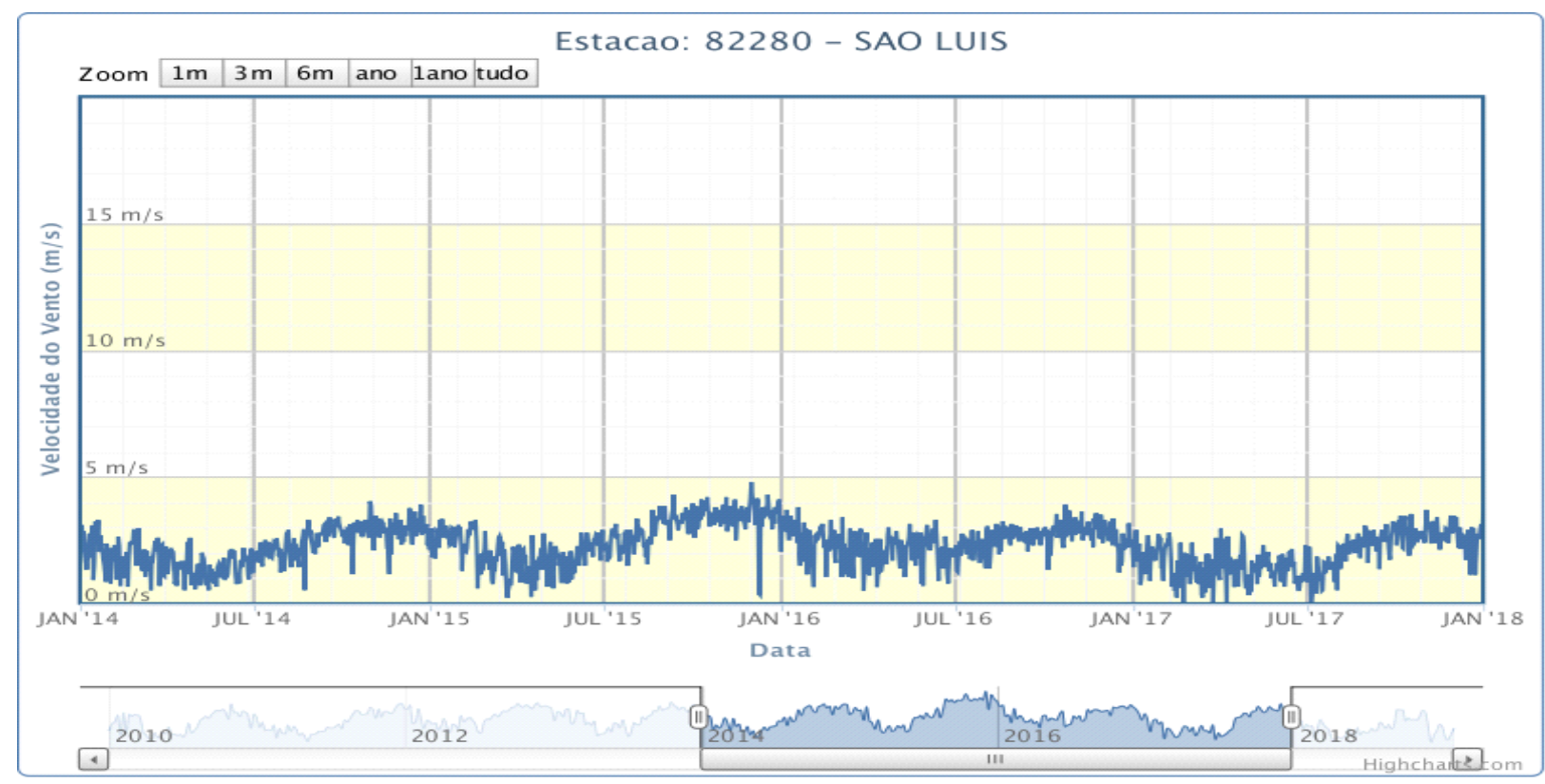

Fonte: INMET - Instituto Nacional de Meteorologia.

Observa-se que a velocidade dos ventos apresentou variações estáveis se mantendo com médias abaixo de $5 \mathrm{~m} / \mathrm{s}$ ao longo do período avaliado.

\section{- Resultados do monitoramento ocupacional}

Todas as avaliações de Poeira Respirável utilizadas neste estudo, foram coletadas ao longo do mês de novembro de 2018.

O monitoramento foi realizado durante as atividades laborais rotineiras de profissionais que atuam na manutenção preventiva e corretiva de equipamentos locados no pátio de estocagem de minério de ferro. Estes profissionais atuam nas disciplinas de elétrica, mecânica 
Research, Society and Development, v. 9, n.2, e05921873, 2020

(CC BY 4.0) | ISSN 2525-3409 | DOI: http://dx.doi.org/10.33448/rsd-v9i2.1873

e civil, e suas atividades não foram alteradas em nenhum momento, em virtude da coleta de amostras do ar respirado, em seus respectivos locais de trabalho.

Foram analisados paradigmas de $3 \mathrm{GHE}$ - Grupo Homogêneo de Exposição, perfazendo um total de 13 amostras coletadas nos dias $01,16,17,20,21$ e 22 de nov/2018.

Abaixo, os resultados das avaliações dos GHE observados. Nos Quadros 2, 3 e 4.

Quadro 2 - GHE -1

\begin{tabular}{|c|c|c|c|c|c|c|c|c|c|c|}
\hline \multirow{2}{*}{ Av. } & \multirow{2}{*}{ Data } & \multirow{2}{*}{$\begin{array}{l}\text { T. Monit. } \\
\text { (h:mm) }\end{array}$} & \multirow{2}{*}{$\begin{array}{c}\text { Mat. Emp. } \\
\text { Avaliado }\end{array}$} & \multirow{2}{*}{ Amostra } & \multicolumn{2}{|c|}{ Conc. $\left(\mathrm{mg} / \mathrm{m}^{3}\right)$} & \multirow{2}{*}{$\mathrm{SiO2}(\%)$} & \multirow{2}{*}{$\begin{array}{l}\text { LT NR15 } \\
\left(\mathrm{mg} / \mathrm{m}^{3}\right)\end{array}$} & \multirow{2}{*}{ Tipo } & \multirow{2}{*}{ Relatório $\mathrm{N}^{0}$} \\
\hline & & & & & $\mathrm{SiO2}$ & Poeira & & & & \\
\hline 1 & $01 / 11 / 2017$ & $06: 00: 00$ & 500624 & 2001700542 & 0,004 & 0,062 & 6 & 0,947 & Respirável & SB1702651.085 \\
\hline 2 & $01 / 11 / 2017$ & 01:43 & 547457 & 2001700536 & 0,004 & 0,049 & 8 & 0,787 & Respirável & SB1702651.083 \\
\hline 3 & $01 / 11 / 2017$ & $06: 20: 00$ & 545712 & 2001700575 & 0,004 & 0,364 & 1 & 2,582 & Respirável & SB1702651.081 \\
\hline \multirow[t]{3}{*}{4} & 16/11/2017 & $06: 00: 00$ & 540148 & 2001700556 & 0,004 & 0,049 & 1 & 2,582 & Respirável & SB1702651.094 \\
\hline & \multicolumn{5}{|c|}{$\mathrm{SiO2}$} & \multicolumn{5}{|c|}{ Poeira } \\
\hline & $\begin{array}{l}\text { Conc. MG } \\
\left(\mathrm{mg} / \mathrm{m}^{3}\right)\end{array}$ & $\begin{array}{l}\text { LT NR } 15 \\
\left(\mathrm{mg} / \mathrm{m}^{3}\right)\end{array}$ & $\begin{array}{c}\text { LT ACGIH } \\
\left(\mathrm{mg} / \mathrm{m}^{3}\right)\end{array}$ & $\begin{array}{l}\mathrm{P} 95 \% \\
\mathrm{mg} / \mathrm{m}^{3}\end{array}$ & DPG & \begin{tabular}{|c|}
$\begin{array}{c}\text { Conc. MG } \\
\left(\mathrm{mg} / \mathrm{m}^{3}\right)\end{array}$ \\
\end{tabular} & $\begin{array}{l}\text { LT NR 15 } \\
\left(\mathrm{mg} / \mathrm{m}^{3}\right)\end{array}$ & $\begin{array}{c}\text { LT ACGIH } \\
\left(\mathrm{mg} / \mathrm{m}^{3}\right)\end{array}$ & $\begin{array}{l}\mathrm{P} 95 \% \\
\mathrm{mg} / \mathrm{m}^{3}\end{array}$ & DPG \\
\hline 4 & 0,004 & N/A & 0,025 & 0,000 & 0,000 & 0,086 & 1,201 & 3,000 & 0,000 & 0,000 \\
\hline
\end{tabular}

Fonte: Departamento de Higiene Ocupacional de uma mineradora no DISAL

Quadro 3 - GHE - 2

\begin{tabular}{|c|c|c|c|c|c|c|c|c|c|c|}
\hline \multirow{2}{*}{ Av. } & \multirow{2}{*}{ Data } & \multirow{2}{*}{$\begin{array}{l}\text { T. Monit. } \\
\text { (h:mm) }\end{array}$} & \multirow{2}{*}{$\begin{array}{c}\text { Mat. Emp. } \\
\text { Avaliado }\end{array}$} & \multirow{2}{*}{ Amostra } & \multicolumn{2}{|c|}{ Conc. $\left(\mathrm{mg} / \mathrm{m}^{3}\right)$} & \multirow{2}{*}{$\mathrm{SiO}(\%)$} & \multirow{2}{*}{$\begin{array}{l}\text { LT NR15 } \\
\left(\mathrm{mg} / \mathrm{m}^{3}\right)\end{array}$} & \multirow{2}{*}{ Tipo } & \multirow{2}{*}{ Relatório $\mathrm{N}^{0}$} \\
\hline & & & & & $\mathrm{SiO2}$ & Poeira & & & & \\
\hline 1 & $17 / 11 / 2017$ & $06: 00$ & 512655 & 2001700554 & 0,004 & 0,030 & 13 & 0,522 & Respirável & SB1703106.004 \\
\hline 2 & $17 / 11 / 2017$ & $06: 00$ & 734053 & 2001700551 & 0,004 & 0,050 & 8 & 0,800 & Respirável & SB1703106.005 \\
\hline 3 & $17 / 11 / 2017$ & $06: 00$ & 547416 & 2001700571 & 0,004 & 0,050 & 8 & 0,800 & Respirável & SB1703106.003 \\
\hline 4 & $20 / 11 / 2010$ & 03:30:00 & 501913 & 2001700543 & 0,007 & 0,085 & 8 & 0,782 & Respirável & SB1703106.001 \\
\hline 5 & $20 / 11 / 2017$ & $02: 50: 00$ & 488003 & $2001700565 \mid$ & 0,009 & 0,105 & 9 & 0,757 & Respirável & SB1703106.006 \\
\hline \multirow[b]{2}{*}{$\#$} & \multicolumn{5}{|c|}{$\mathrm{SiO2}$} & \multicolumn{5}{|c|}{ Poeira } \\
\hline & $\begin{array}{c}\text { Conc. MG } \\
\left(\mathrm{mg} / \mathrm{m}^{3}\right)\end{array}$ & $\begin{array}{l}\text { LT NR } 15 \\
\left(\mathrm{mg} / \mathrm{m}^{3}\right)\end{array}$ & $\begin{array}{c}\text { LT ACGIH } \\
\left(\mathrm{mg} / \mathrm{m}^{3}\right)\end{array}$ & $\begin{array}{l}\mathrm{P} 95 \% \\
\mathrm{mg} / \mathrm{m}^{3}\end{array}$ & DPG & $\begin{array}{c}\text { Conc. MG } \\
\left(\mathrm{mg} / \mathrm{m}^{3}\right)\end{array}$ & $\begin{array}{l}\text { LT NR } 15 \\
\left(\mathrm{mg} / \mathrm{m}^{3}\right)\end{array}$ & $\begin{array}{c}\text { LT ACGIH } \\
\left(\mathrm{mg} / \mathrm{m}^{3}\right)\end{array}$ & $\begin{array}{l}\mathrm{P} 95 \% \\
\mathrm{mg} / \mathrm{m}^{3}\end{array}$ & DPG \\
\hline 5 & 0,005 & N/A & 0,025 & 0,010 & 1,471 & 0,058 & 0,725 & 3,000 & 0,131 & 1,639 \\
\hline \multicolumn{11}{|c|}{$\begin{array}{l}\text { Legenda: Conc. - Concentração Vol - Volume MG - Média Geométrica DFG - Desvio Padrâo Geométrico P } 95 \% \text { - Percentil } 95 \text { ND- Não Definido Vermelho - } \\
\text { Acima do LT Larania - Entre o NA e LT Verde - Abaino do NA. }\end{array}$} \\
\hline
\end{tabular}

Fonte: Departamento de Higiene Ocupacional de uma mineradora no DISAL 
(CC BY 4.0) | ISSN 2525-3409 | DOI: http://dx.doi.org/10.33448/rsd-v9i2.1873

Quadro 4-GHE - 3

\begin{tabular}{|c|c|c|c|c|c|c|c|c|c|c|}
\hline \multirow{2}{*}{ Av. } & \multirow{2}{*}{ Data } & \multirow{2}{*}{$\begin{array}{l}\text { T. Monit. } \\
\text { (h:mm) }\end{array}$} & \multirow{2}{*}{$\begin{array}{c}\text { Mat. Emp. } \\
\text { Avaliado }\end{array}$} & \multirow{2}{*}{ Amostra } & \multicolumn{2}{|c|}{ Conc. $\left(\mathrm{mg} / \mathrm{m}^{3}\right)$} & \multirow{2}{*}{ SiO2 (\%) } & \multirow{2}{*}{$\begin{array}{l}\text { LT NR15 } \\
\left(\mathrm{mg} / \mathrm{m}^{3}\right)\end{array}$} & \multirow{2}{*}{ Tipo } & \multirow{2}{*}{ Relatório $\mathrm{N}^{0}$} \\
\hline & & & & & $\mathrm{SiO2}$ & Poeira & & & & \\
\hline 1 & $21 / 11 / 2017$ & $06: 00$ & 512819 & 2001700555 & 0,004 & 0,910 & 0 & 4,000 & Respirável & SB1703106.007 \\
\hline 2 & $21 / 11 / 2017$ & $02: 30$ & 513625 & 2001700561 & 0,010 & 0,119 & 8 & 0,800 & Respirável & SB1703106.002 \\
\hline 3 & $22 / 11 / 2017$ & $06: 00$ & 513625 & 2001700573 & 0,004 & 0,050 & 1 & 2,667 & Respirável & SB1703106.011 \\
\hline 4 & $22 / 11 / 2017$ & $05: 30: 00$ & 512917 & $\mid 2001700534$ & 0,005 & 0,132 & 4 & 1,333 & Respirável & SB1703106.010 \\
\hline \multirow[b]{2}{*}{$\#$} & \multicolumn{5}{|c|}{$\mathrm{SiO2}$} & \multicolumn{5}{|c|}{ Poeira } \\
\hline & $\begin{array}{c}\text { Conc. MG } \\
\left(\mathrm{mg} / \mathrm{m}^{3}\right)\end{array}$ & $\begin{array}{l}\text { LT NR } 15 \\
\left(\mathrm{mg} / \mathrm{m}^{3}\right)\end{array}$ & $\begin{array}{c}\text { LT ACGIH } \\
\left(\mathrm{mg} / \mathrm{m}^{3}\right)\end{array}$ & $\begin{array}{l}\mathrm{P} 95 \% \\
\mathrm{mg} / \mathrm{m}^{3}\end{array}$ & DPG & $\begin{array}{l}\text { Conc. MG } \\
\left(\mathrm{mg} / \mathrm{m}^{3}\right)\end{array}$ & $\begin{array}{l}\text { LT NR } 15 \\
\left(\mathrm{mg} / \mathrm{m}^{3}\right)\end{array}$ & $\begin{array}{c}\text { LT ACGIH } \\
\left(\mathrm{mg} / \mathrm{m}^{3}\right)\end{array}$ & $\begin{array}{l}\mathrm{P} 95 \% \\
\mathrm{mg} / \mathrm{m}^{3}\end{array}$ & DPG \\
\hline 4 & 0,005 & N/A & 0,025 & 0,010 & 1,517 & 0,164 & 1,585 & 3,000 & 1,225 & 3,402 \\
\hline
\end{tabular}

Fonte: Departamento de Higiene Ocupacional de uma mineradora no DISAL

Como podemos verificar nos quadros acima, nenhuma amostra coletada no pátio de estocagem de minério de ferro, ultrapassou o limite de tolerância indicado pela NR-15, para Poeira Respirável. Sendo assim, o pátio de estocagem de minério de ferro, local onde foram coletadas todas as amostras, foi classificado como área SALUBRE, frente a legislação trabalhista vigente, ou seja, nesta área não há exposição ao risco químico poeira mineral, em grau suficiente para causar problemas ocupacionais ao trabalhador.

- Análise da Precipitação Pluviométrica

Em novembro de 2018, entre os dias 1 e 22, período em que todas as avaliações de Poeira Respirável utilizadas neste estudo foram realizadas, o comportamento das chuvas foi idêntico aos relatados na ocasião do monitoramento ambiental, conforme gráfico abaixo, obtido no INMET - Instituto Nacional de Meteorologia na Estação 82280, localizada em São Luís - MA, conforme na Figura 9. 
Figura 9 - Velocidade dos ventos referente ao mês de novembro de 2018

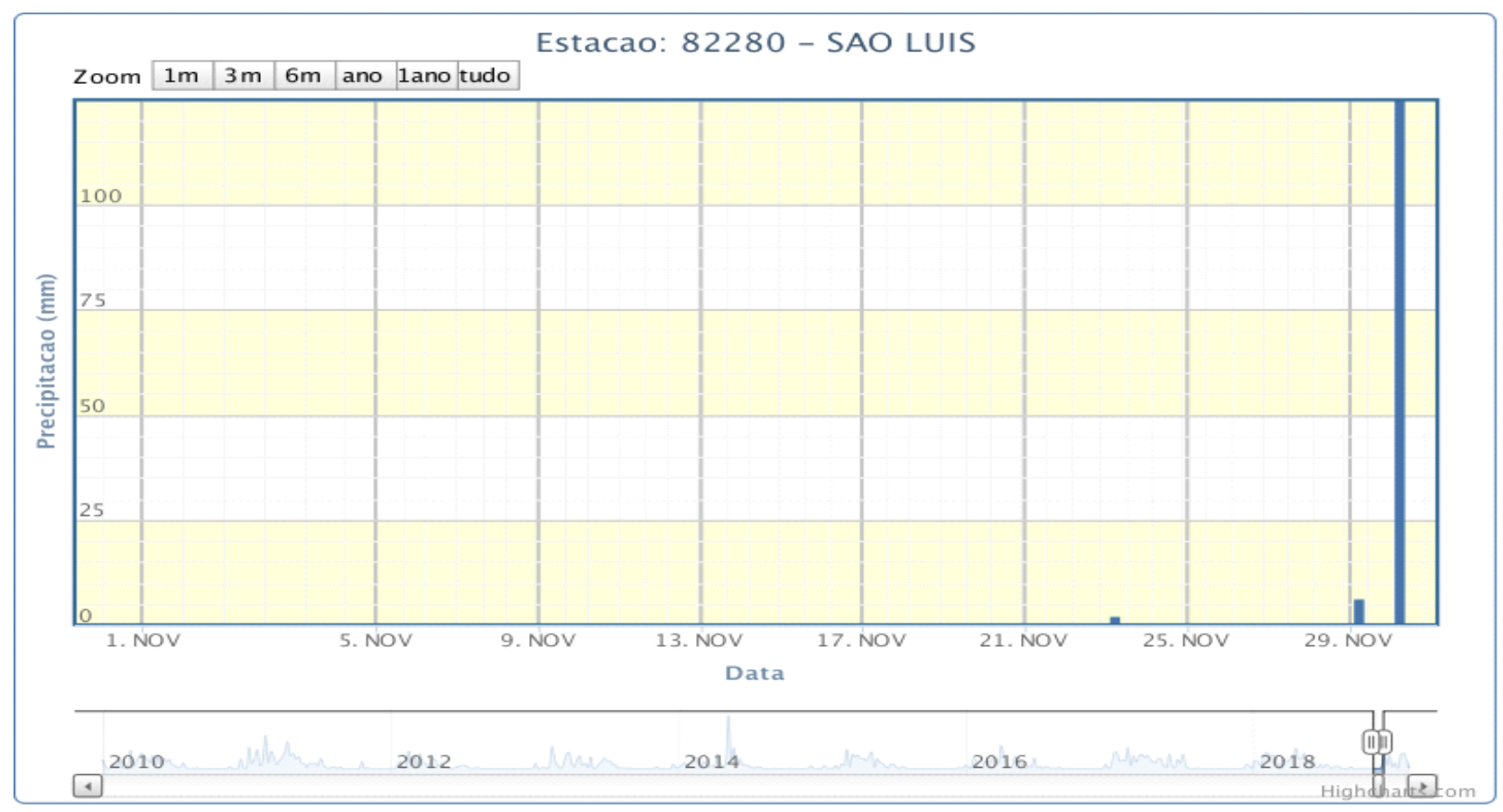

Fonte: INMET - Instituto Nacional de Meteorologia

Observa-se no gráfico acima, que não houve precipitação pluvial no período monitorado, otimizando o cenário para as avalições atmosféricas pretendidas e observadas na Figura 6 que mostra os índices pluviométricos referente aos anos 2014 a 2017.

- Análise dos Ventos

Todas as avaliações de Poeira Respirável utilizadas neste estudo, foram realizadas em novembro de 2018, conforme Figura 10. 
Research, Society and Development, v. 9, n.2, e05921873, 2020

(CC BY 4.0) | ISSN 2525-3409 | DOI: http://dx.doi.org/10.33448/rsd-v9i2.1873

Figura 10 - Velocidade dos ventos referente ao mês de novembro de 2018

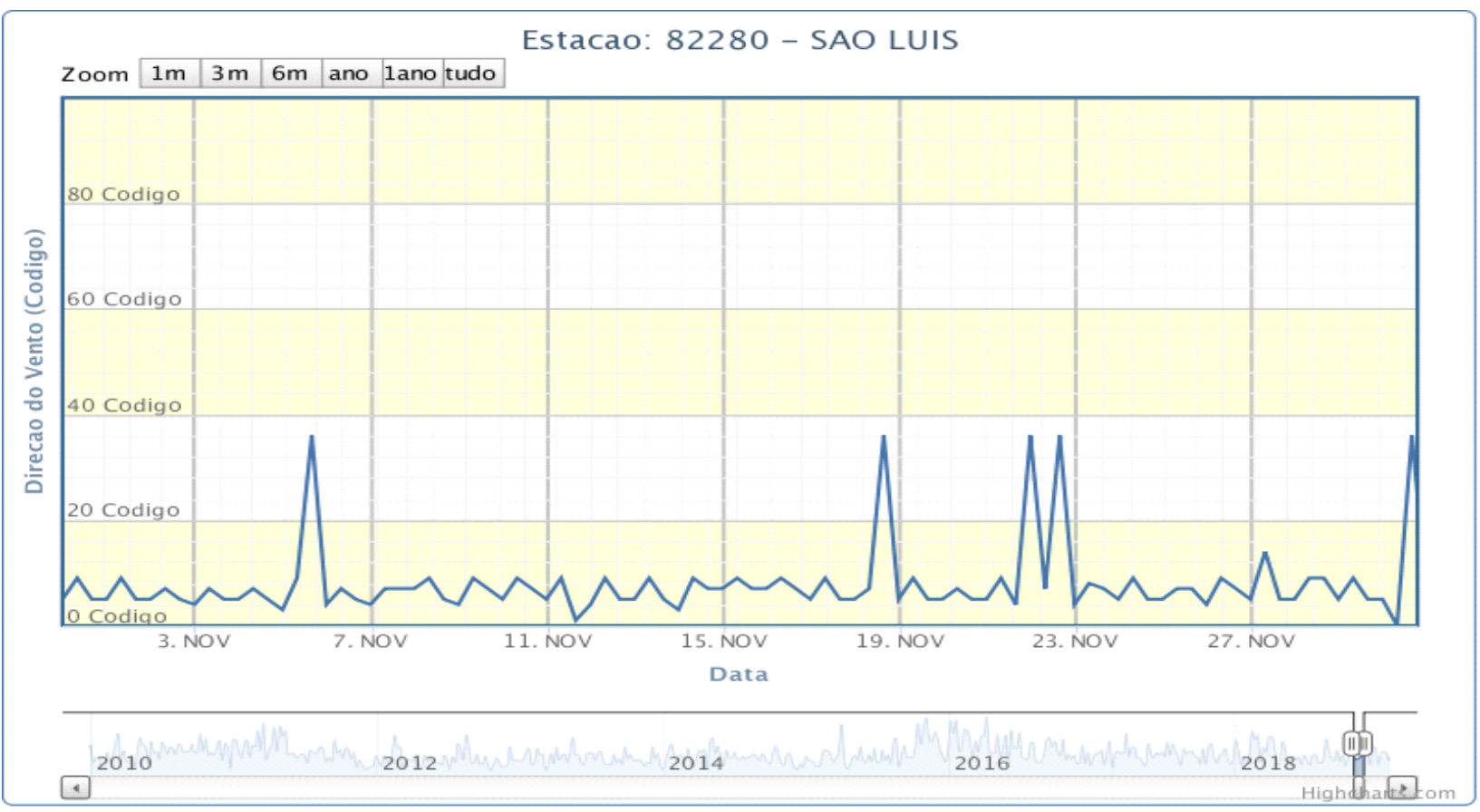

Fonte: INMET - Instituto Nacional de Meteorologia

Conforme observado no gráfico acima, durante o mês de novembro de 2018 os ventos predominantes foram das direções Nordeste (NNE) e Nordeste (NE), refletindo a variação observada na Figura 7, referente no período de 2014 a 2017.

Figura 11 - Velocidade dos ventos referente ao mês de novembro de 2018

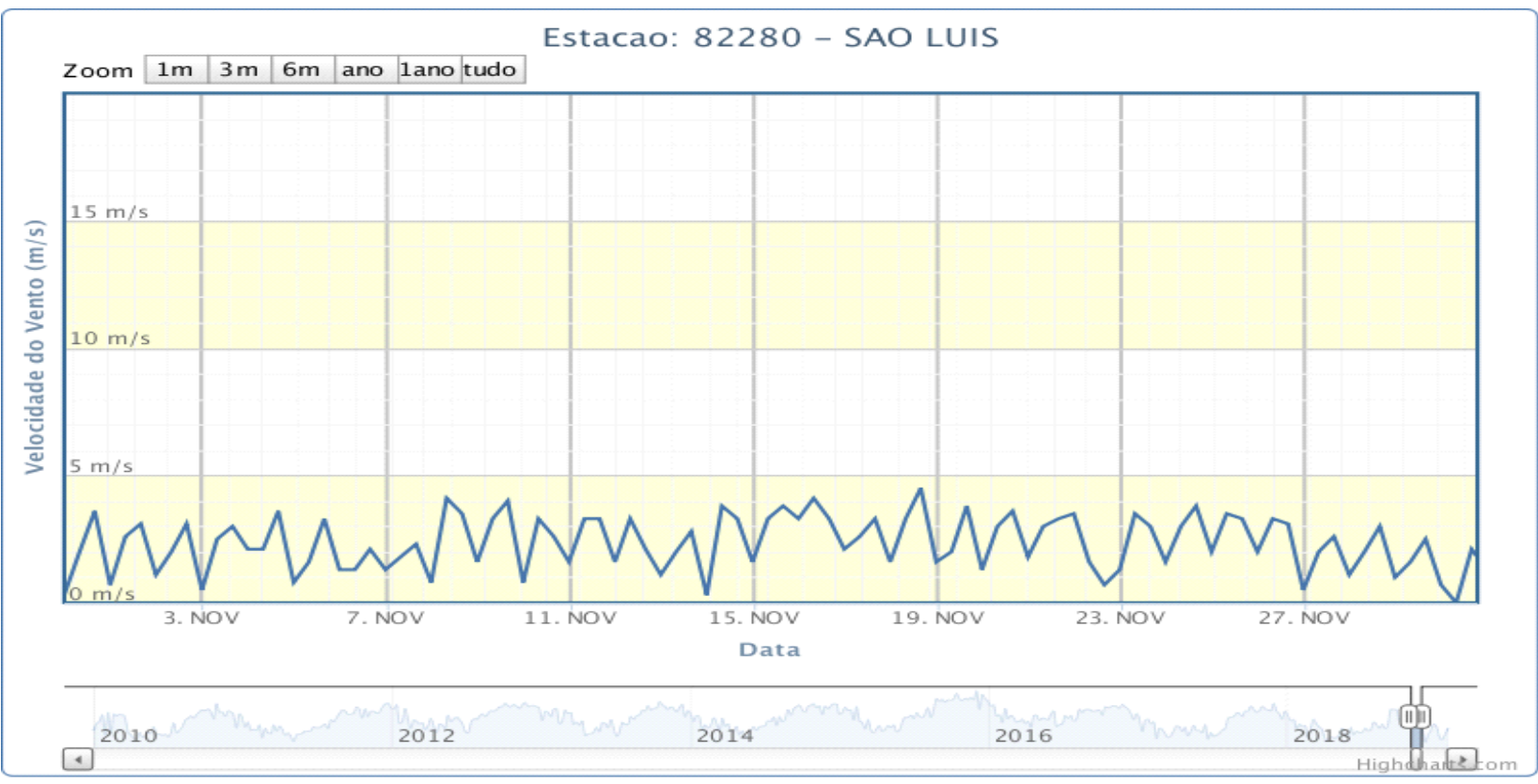

Fonte: INMET - Instituto Nacional de Meteorologia. 
Research, Society and Development, v. 9, n.2, e05921873, 2020

(CC BY 4.0) | ISSN 2525-3409 | DOI: http://dx.doi.org/10.33448/rsd-v9i2.1873

Como se pode observar na figura acima, neste período os ventos permaneceram com velocidades regulares, com médias abaixo de $5 \mathrm{~m} / \mathrm{s}$, replicando o resultado encontrado no período de 2014 a 2017 e apresentado na Figura 8.

\section{Considerações finais}

Apesar do resultado da avaliação ambiental referente à Poeira Inalável, realizada entre 2014 e 2017, ter ultrapassado os limites de tolerância estipulados pela Resolução CONAMA 003/1990, na área próxima à estação de monitoramento da EMAP, o resultado da avaliação de Poeira Respirável realizado em conformidade com a NR-15, classificou o pátio de estocagem de minério de ferro, localizado entre as 2 estações monitoradas, como SALUBRE, ou seja, apto para se trabalhar.

Conclui-se que especificamente neste pátio de estocagem de minério de ferro, localizado no DISAL, a legislação ambiental foi mais restritiva que a trabalhista e considerando apenas este estudo, podemos afirmar que no tocante a poluição atmosférica, para uma área ser classificada como SALUBRE ocupacionalmente, independe do resultado ambiental desta mesma área, quando se trata de qualidade do ar.

Para uma próxima oportunidade de pesquisa, seria interessante obter resultados de monitoramento ambiental e ocupacional de outras áreas, afim de verificar outras possíveis relações entre os resultados analisados.

\section{Referências}

Abdollah, G.M. \& Javad, F.N.S, (2012). Occupational Exposure Determination To Silica Dust In An Iron - Stone Ore And Comparison With Standard, 4(6): 1141-1149, https://www.ingentaconnect.com/content/doaj/18404529/00000004/0000

Arasteh, H. \& Saeedi, G. (2016). Studying Hygienic Status of Mechanized Long Wall Face from the Perspective of the Existing Dust Containing Silica in Tabas Coal Mine. Geotechnical And Geological Engineering, [s.1.], 35(1): 213-224, 4 out. Springer Nature. http://dx.doi.org/10.1007/s10706-016-0099-2. 
Elzinga, Evert J. et al. (2011). Iron speciation in urban dust. Atmospheric Environment. 45(2)26: 4528-4532, ISSN 1352-2310, https://doi.org/10.1016/j.atmosenv.2011.05.042.

Fundacentro (2009). Higiene Ocupacional, NHO 08: Coleta de Material particulado sólido suspenso no ar de ambientes de trabalho, Procedimento Técnico, São Paulo, $1^{a}$ Ed. Ministério do Trabalho e Emprego.

Furieri, B. et al. (2013). Aeolian erosion of storage piles yards: contribution of the surrounding areas. Environmental Fluid Mechanics, [s.1.], v. 14, n. 1, p.51-67, 19 jun. Springer Nature. http://dx.doi.org/10.1007/s10652-013-9293-4.

Goto, M. M. et al. (2018). A Qualidade Do Ar E Materiais Particulados Nos Portos Do Itaqui E Ponta Da Madeira - São Luís (MA). Revista de Ciência \& Tecnologia, Piracicaba, v. 21, n. 41, p.103-116. Semestral. <http://dx.doi.org/10.15600/2238-1252/rct.v21n41p1-2

Huertas, J. I.; Huertas, M. E.; Solís, D. A. (2012). Characterization of airborne particles in an open pit mining region. Science of The Total Environment, Volume 423, Pages 39-46, ISSN 0048-9697, https://doi.org/10.1016/j.scitotenv.2012.01.065.

Janae, C.; Jason F.; Mark, P; Taylor, S. G.; Andrea, L.; Eric A, Betterton; A, Eduardo S. (2012). A review on the importance of metals and metalloids in atmospheric dust and aerosol from mining operations. Science of The Total Environment, Volume 433, Pages 58-73, ISSN 0048-9697, HYPERLINK "https://doi.org/10.1016/j.scitotenv.2012.06.013"itotenv.2012

Jon Roberts e Peter W. (2018). Research, Development and Application of Dust Suppression Technology. Proceedings of the 18th Coal Operators' Conference, Mining Engineering, University of Wollongong, February, Pages 319-328.

Ministério do meio ambiente. (2018). Conama. Resolução $n^{\circ}$ 003/1990. Retrieved Mar 10, 2018, from http://www.mma.gov.br/port/conama/res/res90/res0390.html.

Ministério do trabalho e emprego. (2009). MTE. Norma Regulamentadora. NR-15 Atividades e Operações Insalubres. Retrieved nov 10, 2009, from 
Research, Society and Development, v. 9, n.2, e05921873, 2020

(CC BY 4.0) | ISSN 2525-3409 | DOI: http://dx.doi.org/10.33448/rsd-v9i2.1873

http://www.trabalho.gov.br/seguranca-e-saude-no-trabalho/normatizacao/normas-

regulamentadoras/norma-regulamentadora-n-15-atividades-e-operacoes-insalubres.

Noble, T. L. et al. (2016). Mineral Dust Emissions at Metalliferous Mine Sites, Environmental Indicators in Metal Mining. p. 281-306, Springer International Publishing, https://doi.org/10.1007/978-3-319-42731-7_16.

Tapia, J. S.; Valdés, J. O. R.; Tchernitchin, A.; Dorador, C., Bolados, A.; Harrod, C., (2018). Geologic and anthropogenic sources of contamination in settled dust of a historic mining port city in northern Chile: health risk implications. PeerJ 6:e4699 https://doi.org/10.7717/peerj.4699.

Cong, X. C., Yang, S. L., Cao, S.Q., Chen, Z. L., Dai, M. X., Peng., S. T., (2012). Effect of aggregate stockpile configuration and layout on dust emissions in an open yard. Applied Mathematical Modelling, Volume 36, Issue 11, Pages 5482-5491, ISSN 0307-904X, https://doi.org/10.1016/j.apm.2012.01.014.

\section{Porcentagem de contribuição de cada autor no manuscrito}

Luiz Paulo Costa Faria - 95\%

Cláudio José Cavalcante Blanco - 05\% 